\title{
Bioelectrical impedance assay to monitor changes in cell shape during apoptosis
}

\author{
Silke Arndt, Jochen Seebach ${ }^{1}$, Katherina Psathaki, Hans-Joachim Galla, Joachim Wegener* \\ Institut für Biochemie, Westfälische Wilhelms-Universität Münster, Wilhelm-Klemm Str. 2, 48149 Münster, Germany
}

Received 22 January 2003; received in revised form 3 June 2003; accepted 8 July 2003

\begin{abstract}
Apoptosis is a strictly regulated and genetically encoded cell 'suicide' that may be triggered by cytokines, depletion of growth factors or certain chemicals. It is morphologically characterized by severe alterations in cell shape like cell shrinkage and disintegration of cell-cell contacts. We applied a non-invasive electrochemical technique referred to as electric cell-substrate impedance sensing (ECIS) in order to monitor the apoptosis-induced changes in cell shape in an integral and quantitative fashion with a time resolution in the order of minutes. In ECIS the cells are grown directly on the surface of small gold-film electrodes $(d=2 \mathrm{~mm})$. From readings of the electrical impedance of the cell-covered electrode, performed with non-invasive, low amplitude sensing voltages, it is possible to deduce alterations in cell-cell and cell-substrate contacts. To improve the sensitivity of this impedance assay we used endothelial cells derived from cerebral micro-vessels as cellular model systems since these are well known to express electrically tight intercellular junctions. Apoptosis was induced by cycloheximide $(\mathrm{CHX})$ and verified by biochemical and cytological assays. The time course of cell shape changes was followed with unprecedented time resolution by impedance readings at $1 \mathrm{kHz}$ and correlated with biochemical parameters. From impedance readings along a broad frequency range of $1-10^{6} \mathrm{~Hz}$ we could assign the observed impedance changes to alterations on the subcellular level. We observed that disassembly of barrier-forming tight junctions precedes changes in cell-substrate contacts and correlates strongly with the time course of protease activation. (C) 2003 Elsevier B.V. All rights reserved.
\end{abstract}

Keywords: Impedance analysis; ECIS; Whole-cell biosensor; Apoptosis; Cell-cell contacts; Cell-substrate contacts

\section{Introduction}

Apoptosis and necrosis are two different pathways for animal cells to die. Whereas apoptosis is a strictly regulated, genetically encoded and evolutionary selected active cell 'suicide' that mediates the safe and controlled deletion of unwanted cells, necrosis is more a passive, 'accidental' and pathological cell death (Wyllie et al., 1980). Necrosis is not believed to ever occur in a living organism under strictly physiological conditions but it does occur when cells are severely poisoned or compromised by other external factors. In contrast, apoptosis is as important for the normal development of multicellular organisms as cell division and differentiation and it is regarded as the indispensable counterpart to mitosis. For example, $10^{11}$ cells die by apoptosis

\footnotetext{
* Corresponding author. Tel.: +49-251-833-9765; fax: +49-251-833-3206.

E-mail address: wegenej@uni-muenster.de (J. Wegener).

1 Present address: Institut für Physiologie, Med. Fakultät Carl-GustavCarus, Fetscherstr. 74, 01307 Dresden, Germany.
}

in a human body per day to ensure tissue homeostasis, so that within a typical year a person loses as many cells by apoptosis as corresponds to its total body weight (Wu et al., 2001). Disturbances in a cell's ability to undergo apoptosis may lead to severe pathologies most notably the progression and growth of solid tumors (Thompson, 1995). In most recent reports apoptosis is also more and more considered when cell death induced by toxic chemicals in moderate concentrations is discussed (Zaucke et al., 1998; Robertson and Orrenius, 2000).

Apoptosis and necrosis can be clearly distinguished from each other by several morphological and biochemical features (Gobe and Harmon, 2001; McConkey, 1998). Apoptotic cells shrink without loosing the integrity of their plasma membrane. In vivo they are then removed and digested by phagocytic cells. In contrast, necrotic cells swell and their plasma membrane eventually ruptures so that cytoplasmic molecules escape into the extracellular space and induce a subsequent inflammatory response in the surrounding tissue. Apoptotic cells are known to loosen contacts to their neighbors, form cytoplasmic vacuoles, show nuclear and plasma 
membrane blebbing, a characteristic chromatin condensation and DNA fragmentation (Gobe and Harmon, 2001; McConkey, 1998). Many of these processes along the apoptotic pathway are mediated or transmitted by a family of intracellular cysteinyl-aspartate-specific proteinases, called caspases. These enzymes are subdivided into either initiator or effector caspases dependent on their individual role and targets (Leist and Jaattela, 2001; Takahashi, 1999). Initiator caspases are capable of proteolytically cleaving inactive pro-caspases, whereas effector caspases directly cleave certain target proteins within the cell and induce the concomitant structural and functional alterations. Caspase- 3 is probably the most relevant and efficient effector caspase and is, thus, also called the death caspase.

Since apoptosis plays such a crucial role in many physiological or pathophysiological processes, the underlying mechanisms are studied extensively. In the light of this background it was our objective to develop a new bio-analytical assay to monitor apoptosis in cultured cells non-invasively and in real time. As the three-dimensional shape of adherent cells is a very sensitive indicator for their viability or any deteriorating changes in their environment we based the new assay on a shape-sensitive electrochemical technique that is referred to as electric cell-substrate impedance sensing (ECIS) (Giaever and Keese, 1993; Keese and Giaever, 1994). In ECIS the cells are grown on gold-film electrodes that are deposited on the surface of ordinary cell culture dishes. Readings of the electrical impedance of the cell-covered electrode allow to extract information about the shape of the cells on the electrode surface quantitatively (Wegener et al., 2000) and with a time resolution that can be reduced to less than a second (Giaever and Keese, 1991). ECIS has been successfully applied to monitor cell shape changes in various cell types under very different experimental conditions. For instance, Tiruppathi et al. (1992) have used ECIS to monitor the morphological response of bovine endothelial cells to the addition of $\alpha$-thrombin and to explore the second messenger pathways involved. The enormous sensitivity of the ECIS device was demonstrated by detecting the morphological alterations of cultured cells caused by the periodic injections of $\mathrm{CO}_{2}$ in ordinary cell culture incubators (Lo et al., 1994). The rapid changes in cell shape that can be induced in human orbital fibroblasts by exposure to prostaglandin E have also been monitored by ECIS and shown to be mediated by cAMP-dependent signal transduction pathways (Reddy et al., 1998).

Our selection of an appropriate cell type as the ultimate sensory elements in an ECIS-based apoptosis assay has been endothelial cells derived from brain capillaries. In vivo these cells line the wall of the cerebral micro-vessels and form the so-called blood-brain barrier, a tight diffusion barrier between the circulating blood and the brain that is responsible for the establishment and maintenance of a constant chemical environment in the central nervous system (Bradbury, 1993). The functionality of the blood-brain barrier is based on the expression of tight cell-cell contacts that occlude the diffusion pathway along the intercellular cleft between two adjacent endothelial cells. Since the tightness of this endothelial barrier, which is accessible from ECIS readings, is extraordinary sensitive for changes in cell shape we used monolayers of these particular cells as a transducer within a bioelectrical hybrid device. This whole-cell biosensor is designed to read apoptosis-induced changes in biological activity independent of the trigger mechanism in a strictly physiological environment.

\section{Materials and Methods}

\subsection{Cell preparation and culture conditions}

Endothelial cells of cerebral micro-vessels were isolated from pig brain (porcine brain capillary endothelial cells (PBCECs)) as described previously (Franke et al., 2000). Briefly, cerebra of freshly slaughtered pigs were mechanically homogenized and gradually digested by two proteases, together with further purification steps including density centrifugation.

PBCECs suspended in M199 Eagle's medium supplemented with $10 \%(\mathrm{v} / \mathrm{v})$ ox serum, $0.7 \mathrm{mM}$ L-glutamine, $100 \mu \mathrm{g} / \mathrm{ml}$ penicillin and $100 \mathrm{U} / \mathrm{ml}$ streptomycin (all purchased from Biochrom, Berlin) were seeded in a density of 100,000 cells $/ \mathrm{cm}^{2}$ on gelatine-coated gold-film electrodes which are described in more detail below. Cell adhesion to the substrate was found to be most stable when the gelatine was cross-linked by brief exposure to $2.5 \%$ (v/v) glutaraldehyde for $15 \mathrm{~min}$. Subsequently glutaraldehyde was washed out thoroughly with ultrapure water and the electrodes were soaked in water over night prior to inoculation. On the third day after inoculation complete medium was replaced by serum-free medium (SFM) made from Dulbecco's Modified Eagle's Medium F12 (Cell Concepts GmbH, Umkirch, Germany) supplemented with $100 \mu \mathrm{g} / \mathrm{ml}$ penicillin, $100 \mathrm{U} / \mathrm{ml}$ streptomycin, and $100 \mu \mathrm{g} / \mathrm{ml}$ gentamicin. In experiments addressing the anti-apoptotic activity of the glucocorticoid hydrocortisone (HC) the medium was additionally supplemented with $550 \mathrm{nM} \mathrm{HC}$. Medium exchange had to be performed extremely careful since the cell monolayers responded very sensitively to any mechanical challenges. All experiments of this study have been performed with confluent (i.e. continuous and densely packed) cell monolayers.

\subsection{Induction of apoptosis}

We used cycloheximide (CHX; Sigma-Aldrich, Deisenhofen, Germany) to induce apoptosis in PBCECs. Stock solutions were prepared in DMSO with a CHX concentration of $100 \mathrm{mM}$. The final concentration of CHX in the culture medium was adjusted to $25 \mu \mathrm{M}$. Introduction of DMSO into the cell culture medium was always less than $0.05 \%(\mathrm{v} / \mathrm{v})$ throughout the experiments, which by itself did not induce 
any morphological response of the cells. The incubation times are shown with the results.

\subsection{DNA fragmentation}

In order to detect apoptosis-induced DNA fragmentation we used the so-called Cell Death Detection ELISAPLUS (Roche, Mannheim, Germany). After exposure of confluent PBCEC to $25 \mu \mathrm{M}$ CHX or the corresponding DMSO vehicle control for the indicated time the cells were harvested with a cell-scraper. $5 \times 10^{4}$ cells were first re-suspended in $1 \mathrm{ml}$ of the kit's lysis buffer for about $30 \mathrm{~min}$ and were then collected by centrifugation at $200 \times g$. The principle of this assay is to transfer $20 \mu \mathrm{l}$ of the supernatant into a streptavidin-coated 96-well microtiterplate. Subsequently a mixture of biotin-labeled anti-histone and peroxidase-labeled anti-DNA antibodies were added. During the incubation period, the anti-histone antibody binds to the histone component of the nucleosomes and simultaneously immobilizes the immuno-complex to the streptavidin-coated bottom of the titer plate via its biotin residue. Additionally, the anti-DNA-POD antibody reacts with the DNA-component of the nucleosomes. In order to determine quantitatively the amount of nucleosomes bound to the titerplate walls, 2,2'-acinobis[3-ethylbenzthiazoline-sulfonic acid] (ABTS), a POD-substrate, is added after some washing cycles. The amount of the ABTS conversion product was then photometrically quantified $(405 \mathrm{~nm})$.

\subsection{Specific activity of caspase-3}

The CaspACE ${ }^{\mathrm{TM}}$ Assay System Fluorometric (Promega, Heidelberg, Germany) was applied to quantify the activity of caspase-3. After exposure of confluent PBCECs to $25 \mu \mathrm{M}$ CHX or a corresponding DMSO vehicle control for the indicated time the cells were first harvested with a cell-scraper and were then permeabilized in lysis buffer by four repeats of freezing (liquid nitrogen) and thawing $\left(37^{\circ} \mathrm{C}\right)$. The lysis buffer contains $25 \mathrm{mM}$ HEPES (pH 7.5) (Sigma-Aldrich), $5 \mathrm{mM} \mathrm{MgCl} 2 \cdot 6 \mathrm{H}_{2} \mathrm{O}$ (Merck, Darmstadt, Germany), 5 mM EDTA (Fluka, Neu-Ulm, Germany), $5 \mathrm{mM}$ dithiothreitol (Sigma-Aldrich) and a protease inhibitor cocktail tablet (complete EDTA-free, Boehringer Mannheim $\mathrm{GmbH}$, Mannheim, Germany). After centrifugation (15 min, $5^{\circ} \mathrm{C}$ and $14,000 \times g$ ) the cell extract was incubated with a caspase-3 substrate called Ac-DEVD-AMC. This substrate consists chemically of two parts: the caspase-3 specific oligopeptide DEVD (Asp-Glu-Val-Asp) and the fluorochrome AMC (7-amino-4-methyl coumarin). AMC is released upon cleavage of Ac-DEVD-AMC by caspase-3 and shows then a yellow-green fluorescence (excitation $=360 \mathrm{~nm}$, emission $=460 \mathrm{~nm}$ ) which can be used to quantify the caspase- 3 activity. To guarantee the comparability of different samples, fluorescence data were normalized with respect to the protein concentration in the sample. Protein concentrations were determined according to the Lowry approach.

\subsection{Immuno-staining for the tight junctions associated protein $\mathrm{ZO}-1$ and occludin}

Confluent monolayers of PBCEC grown on collagen G-coated cover slips in SFM with or without HC for 3 days were washed twice with phosphate-buffered saline containing $1 \mathrm{mM} \mathrm{Ca}^{2+}$ and $0.5 \mathrm{mM} \mathrm{Mg}^{2+}\left(\mathrm{PBS}^{++}\right)$. Cells were fixed with $4 \%(\mathrm{w} / \mathrm{v})$ paraformaldehyde in $\mathrm{PBS}^{++}$for $10 \mathrm{~min}$ at room temperature (RT) and then washed again with $\mathrm{PBS}^{++}$. The cell membranes were permeabilized by incubation with $0.2 \%(\mathrm{v} / \mathrm{v})$ Triton-X-100 in $\mathrm{PBS}^{++}$for $10 \mathrm{~min}$ at RT. After washing with $\mathrm{PBS}^{++}$the samples were exposed to a solution containing $3 \%(\mathrm{w} / \mathrm{v})$ bovine serum albumin in $\mathrm{PBS}^{++}$for $20 \mathrm{~min}$ at RT to block unspecific binding sites. The first antibodies $(10 \mu \mathrm{g} / \mathrm{ml}$ monoclonal rat anti-zonula occludens protein 1 (ZO-1), Chemikon, Bad Nauheim, Germany; $1.25 \mu \mathrm{g} / \mathrm{ml}$ polyclonal rabbit anti-occludin, Zymed, San Francisco, CA) were applied in a $0.5 \%$ bovine serum albumin/PBS ${ }^{++}$solution for $90 \mathrm{~min}$ at RT. Cells were then washed with $\mathrm{PBS}^{++}$and incubated with $3 \%$ bovine serum albumin/PBS ${ }^{++}$solution for $20 \mathrm{~min}$ at RT again. After being washed with $\mathrm{PBS}^{++}$the cells were incubated with fluorochrome-labeled secondary antibodies $(10 \mu \mathrm{g} / \mathrm{ml}$ rhodamine-labeled, polyclonal anti-rat IgG, Sigma-Aldrich, Deisenhofen, Germany; $10 \mu \mathrm{g} / \mathrm{ml}$ bodipy-labeled polyclonal anti-rabbit IgG, Molecular Probes, Eugene, OR) for $45 \mathrm{~min}$ at RT. Finally cells were washed three times with $\mathrm{PBS}^{++}$and fixed with $4 \%$ paraformaldehyde for $10 \mathrm{~min}$ at RT again. After the last fixation step the cover slips were mounted upside down onto glass slides to protect the specimen. Microscopic images were recorded with the confocal laser scanning microscope Leica TSL.

\subsection{Electric cell-substrate impedance sensing (ECIS)}

Changes in the shape of PBCECs during apoptosis were monitored by electric cell-substrate impedance sensing (Giaever and Keese, 1993; Keese and Giaever, 1994). The method is based on measuring non-invasively the frequency-dependent electrical impedance of cell-covered gold-film electrodes along the time course of the experiment. Subsequently morphological information about the cells on the electrode surface may be extracted from the recorded impedance readings by data modeling. The basic idea of the measurement has been described in more detail before (Wegener et al., 2000; Giaever and Keese, 1991) and only a condensed outline is included here. When mammalian cells attach and spread on the surface of a planar gold-film electrode they behave essentially like insulating particles that hinder unrestricted current flow from the electrode into the bulk electrolyte and thereby increase the overall electrode impedance. When the frequency of the applied ac signal is sufficiently high a certain amount of current can capacitively couple through the plasma membranes and get across the cell layer on transcellular pathways. For most frequencies, however, the current has to bypass the cellular bodies. 


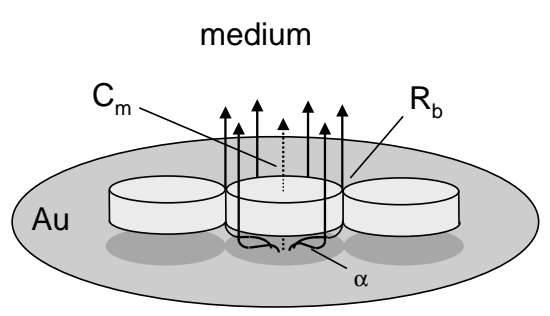

Fig. 1. Schematic of adherent cells on gold-film electrodes. Solid arrows represent paracellular current pathways whereas the broken arrow indicates the transcellular current pathway. The parameters that can be extracted from electrochemical impedance recordings and subsequent data modeling $R_{\mathrm{b}}, \alpha$ and $C_{\mathrm{m}}$ are assigned to their respective cellular origin. Please note that all experiments have been performed with confluent cell layers as shown in Fig. 8. This schematic is confined to three cells for presentational reasons.

Along these paracellular pathways the current needs to flow through the narrow channels between cell and electrode surface before it can escape through the intercellular shunt into the bulk electrolyte (Fig. 1). Accordingly, trans- and paracellular currents experience individual impedance contributions that originate either from the plasma membrane or the cell adhesion zone together with the intercellular cleft. Since the trans- and paracellular impedance contributions are dependent on the frequency of the applied ac signal, they can be separated and quantified individually by impedance measurements over an extended frequency range. Deconvolution of the overall ECIS signal can be performed by fitting a mathematical model that was recently derived by Giaever and Keese (1991) to the experimental data by least-square optimization procedures. In the ECIS-model the impedance contributions of the adherent cell layers are described by three independent parameters. A parameter $R_{\mathrm{b}}$ (resistance between cells) accounts for the impedance contribution arising within the intercellular shunt. Impedance contributions arising from the cell-substrate adhesion zone are accounted for by the parameter $\alpha$ that is defined as

$\alpha=r_{\mathrm{c}} \sqrt{\frac{\rho}{d}}$ with the radius of the cell $r_{\mathrm{c}}$, the specific resistivity of the electrolyte underneath the cell $\rho$ and the distance between membrane and electrode surface $d$. The dielectric properties of the plasma membrane are described by the membrane capacitance $C_{\mathrm{m}}$ (Fig. 1). According to this model, the total impedance of the cell-covered electrode $Z_{\text {total }}$ is described by the equation

$$
\frac{1}{Z_{\text {total }}}=\frac{1}{Z_{\mathrm{n}}}\left\{\frac{Z_{\mathrm{n}}}{Z_{\mathrm{n}}+Z_{\mathrm{m}}}+\frac{Z_{\mathrm{m}} /\left(Z_{\mathrm{n}}+Z_{\mathrm{m}}\right)}{\begin{array}{c}
(1 / 2) \gamma \cdot r_{\mathrm{c}} \cdot\left(I_{0}\left(\gamma r_{\mathrm{c}}\right) / I_{1}\left(\gamma r_{\mathrm{c}}\right)\right) \\
+R_{\mathrm{b}}\left(\left(1 / Z_{\mathrm{n}}\right)+\left(1 / Z_{\mathrm{m}}\right)\right)
\end{array}}\right\}
$$

with

$\gamma=\frac{\alpha}{r_{\mathrm{c}}}\left(\frac{1}{Z_{\mathrm{n}}}+\frac{1}{Z_{\mathrm{m}}}\right)$

$Z_{\mathrm{n}}$ is the impedance of the cell-free gold-film electrode, $Z_{\mathrm{m}}$ the total impedance of both, the apical and basolateral plasma membranes with $Z_{\mathrm{m}}=2 / i \omega C_{\mathrm{m}} \cdot I 0$ and $I_{1}$ are modified Bessel functions of the first kind of order 0 and 1 , respectively. The impedance of the cell-free electrode was derived from the impedance spectra of the cell-covered electrode at the low-frequency end using the empirical constant phase element (CPE) for modeling, thus $Z_{\mathrm{n}}=Z_{\mathrm{CPE}}$. The resistance of the bulk electrolyte which is not included in $Z_{\text {total }}$ and $Z_{n}$ was independently determined from the high frequency end of the spectrum and added to both impedance values.

Fig. 2 sketches the core components of this technique, the measurement chambers, that we build in a somewhat different layout than described for the commercial ECIS electrode arrays (http://www.biophysics.com). The alterations in electrode size and layout are, however, insignificant with respect to the basic ECIS theory and data analysis procedures. The measurement chamber consists of three individual working electrodes $\left(A=3 \mathrm{~mm}^{2}\right)$ and one common, horse-shoe like counter electrode (approx. $3 \mathrm{~cm}^{2}$ ). During the measurement one of the individual working electrodes in combination with the counter electrode form a two-probe system. Since the counter electrode is significantly larger in surface

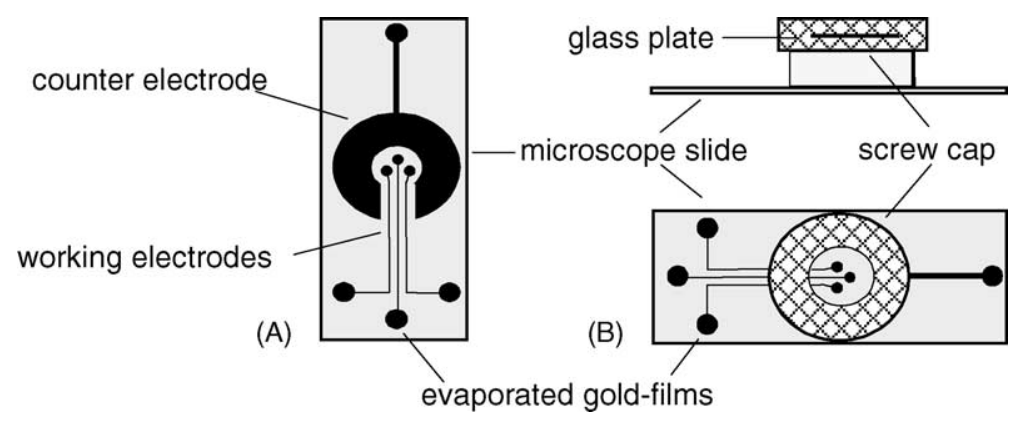

Fig. 2. Measurement chambers to record ECIS data of cell layers grown to confluence on top of integrated gold-film electrodes. (A) Microscope slide with the evaporated gold-film in an arrangement composed of three small working electrodes and one common, horse-shoe like counter electrode. (B) Top and side view of the completed measurement chamber with the electrode holding slide as the chamber bottom. For details of chamber construction see (Wegener et al., 1996). During data recording chambers were placed in a humidified incubator $\left(37^{\circ} \mathrm{C}\right)$. 
area than the working electrode, the total impedance of the system is exclusively dominated by the electrical properties of the cell-covered working electrode and the resistance of the bulk electrolyte. Thus, ECIS data recorded for the three working electrodes provide independent readings from three individual spots within the cell layer. The electrode arrangement is prepared by high-vacuum thermal evaporation of gold through a corresponding mask onto an ordinary microscope slide as described elsewhere (Wegener et al., 1996). A glass top with a screw cap is mounted onto the slide by a non-cytotoxic silicon glue forming a chamber that can be handled like a common cell culture dish (Fig. 2).

Impedance data were recorded in the frequency range between 1 and $10^{6} \mathrm{~Hz}$ using sinusoidal ac voltages of $10 \mathrm{mV}$ amplitude (rms). The dc bias potential between the two identical gold electrodes was clamped to $0 \mathrm{~V}$. The continuous wave impedance analyzer Solatron SI-1260 (Farnborough, UK) was used for all impedance readings. A computer controlled relay board was used to switch between the individual working electrodes of two measuring chambers that were usually followed in parallel. Impedance analyzer and relay board are controlled by a tailor-made software written in LabView. During the experiments the chambers were kept in an ordinary cell culture incubator with a humidified, $\mathrm{CO}_{2}$ supplemented atmosphere (5 vol.\%). Processing of the raw data to extract the parameters $R_{\mathrm{b}}, \alpha$ and $C_{\mathrm{m}}$ has been performed as described in more detail elsewhere (Wegener et al., 2000).

\section{Results and discussion}

The majority of existing techniques to monitor apoptosis in vitro is based on fluorescence probes designed to specifically label relevant molecules in apoptotic cells which can then be detected either by fluorescence microscopy or-for suspended cells - by flow cytometry. Other more biochemical assays read the activity of apoptosis-related enzymes like caspase- 3 or determine the degree of DNA fragmentation by means of agarose gel electrophoresis or ELISA techniques. It was the major objective of this study to develop a new bio-analytical technique that is capable of monitoring apoptosis in monolayers of adherent cells non-invasively, in real time and independent of any fluorescent or radioactive probes. Developing a real-time sensor device seemed most valuable to us in order to provide a technical means to study the dynamics of apoptosis rather than just snapshots. Instead of using the activity of one particular enzyme or one particular biochemical reaction as a measure for apoptosis we focused on apoptosis-induced changes in the three-dimensional shape of the cells. The rationale for this approach is based on very detailed electron microscopic (EM) studies that revealed clear morphological changes in apoptotic cells (Gobe and Harmon, 2001) as they have been described in the introduction. The ultrastructural morphology is still regarded as the most reliable method for identi- fication of apoptosis (Gobe and Harmon, 2001). However, instead of using ultrastructural imaging techniques like EM that are confined to a field of view of one or a few cells at the most, we applied the electrochemical ECIS device that is capable of recording average alterations in cell shape integrated over a cell monolayer of hundreds of cells. ECIS has proven to be extraordinary sensitive to changes in cell-cell and cell-substrate contacts (Wegener et al., 1999; Tiruppathi et al., 1992; Lo et al., 1994). Since the shape of individual cells within a confluent monolayer is determined by their various contacts to their nearest neighbors as well as by their molecular interactions with the growth substrate, ECIS should be well suited to monitor the onset and the dynamics of apoptosis. In order to make the assay very sensitive even for subtle changes in cell morphology we used endothelial cells derived from porcine brain micro-vessels (PBCEC) as the sensing elements as introduced above. The functionality of this interfacial tissue is provided by barrier-forming cell-cell contacts, so-called tight junctions. These tight junctions occlude the intercellular cleft between adjacent cells tight enough to impede even the passage of small inorganic ions $\left(\mathrm{Na}^{+}, \mathrm{K}^{+}, \mathrm{Cl}^{-}\right)$(Fromter, 1972). Accordingly, the establishment and modulation of barrier-forming tight junctions can be sensitively measured by their electrical resistance. Consistent with the physiological requirement of a constant ionic environment within the CNS, cerebral endothelial cells are characterized by tight junctions of high electrical resistance which is very sensitive to minute changes or partial disintegration. With the tightness of the intercellular junctions being one of the parameters that is accessible from ECIS readings $\left(R_{\mathrm{b}}\right)$, a bioelectrical hybrid consisting of the ECIS device interfaced to an endothelial cell monolayer of unique barrier properties promises to be a sensitive and physiologically relevant indicator for apoptosis.

In order to trigger apoptosis in a well-defined and reproducible manner, we exposed the cells to cycloheximide. CHX is primarily known as a potent inhibitor of protein biosynthesis. However, dependent on cell type and exact experimental conditions CHX also induces apoptosis as has been shown for peripheral micro-vessel endothelial cells by $\mathrm{Hu}$ et al. (1998). To ensure that CHX also induces apoptosis in PBCEC, we first determined the degree of DNA fragmentation and the specific activity of caspase-3 after PBCEC had been exposed to $25 \mu \mathrm{M}$ CHX for $16 \mathrm{~h}$. Compared to control cells that were only treated with a corresponding dose of DMSO (solvent for CHX) we found a significantly elevated degree of DNA fragmentation (Fig. 3A) and caspase-3 activity (Fig. 3B). A five-fold up-regulation of DNA fragmentation was accompanied by a 20 -fold increase of the specific caspase- 3 activity. Both of these independent biochemical parameters consistently confirm a specific induction of apoptosis as a response to $\mathrm{CHX}$ addition to the culture medium.

The strength of the ECIS technique is its capability to monitor changes in the shape of cultured cells non-invasively. For simply monitoring the cell response 


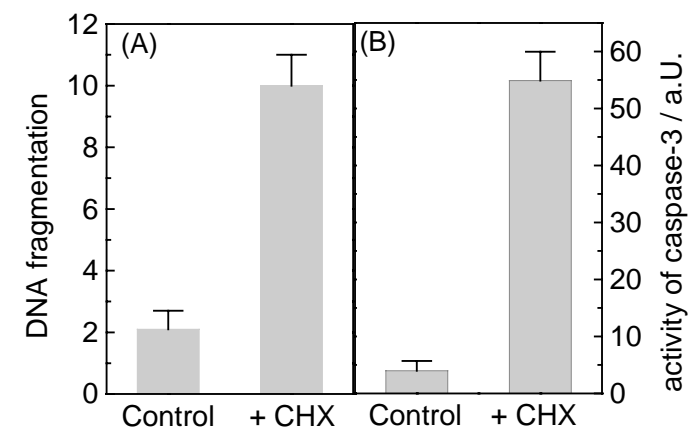

Fig. 3. (A) DNA fragmentation and (B) caspase-3 activity determined for micro-vessel endothelial cells that had been exposed to $25 \mu \mathrm{M}$ cycloheximide (CHX) for $16 \mathrm{~h}$. Control cells were only exposed to an identical dose of DMSO $(0.1 \%)$ that was used as a solvent for cycloheximide.

to any kind of stimulus it is most often sufficient to read the impedance at one designated frequency. But to make an appropriate frequency selection it is instructive to look at the electrical impedance of the cell-covered electrode over an extended frequency range. Fig. 4 shows the raw data of a typical experiment in three-dimensional representation when a confluent layer of PBCEC was exposed to $25 \mu \mathrm{M}$ CHX approximately $0.75 \mathrm{~h}$ after the first impedance spectrum was recorded. Looking along the surface of the data mesh provides the most comprehensive survey on the frequency-dependent changes in electrode impedance when the cells undergo apoptosis and cell-cell and cell-substrate contacts are altered. At the low-frequency end of the spec- trum $(f<10 \mathrm{~Hz})$ the overall impedance of the system is dominated by the impedance of the electrode/electrolyte interface. The impedance at very high frequencies $(f>$ $100 \mathrm{kHz}$ ) is the sum of the resistance of the culture medium, the constriction resistance of the working electrode and all the wiring. Accordingly, the electrical impedance of the system at both ends of the frequency spectrum is independent of the shape and viability of the cells. In the intermediate frequency range the cell bodies dominate the total impedance of the system and consistently the major impedance alterations occur at these frequencies when the apoptosis cascade is released. Please note, that even within the intermediate frequency window $(10 \mathrm{~Hz}<f<100 \mathrm{kHz})$ the time course of the recorded impedance varies for different frequencies. This is due to the fact that the fractional contribution of cell-cell and cell-substrate contacts to the overall impedance is strictly dependent on the frequency of the sensing voltage.

Fig. 5 compares the first and the last impedance spectrum recorded in this experiment in two-dimensional representation. Open circles $(O)$ represent the frequency-dependent impedance before the confluent PBCEC monolayer was exposed to $25 \mu \mathrm{M}$ CHX ( $t=0 \mathrm{~h}$ in Fig. 4 ) whereas the filled circles $(\bullet)$ correspond to the impedance spectrum of the same electrode after the cells have experienced apoptosis-induced changes in cell shape ( $t=15 \mathrm{~h}$ in Fig. 4). Please note that the direction of the frequency axes had to be reversed in Fig. 4 for presentational purposes. As apparent from Fig. 5 the difference in the total impedance between

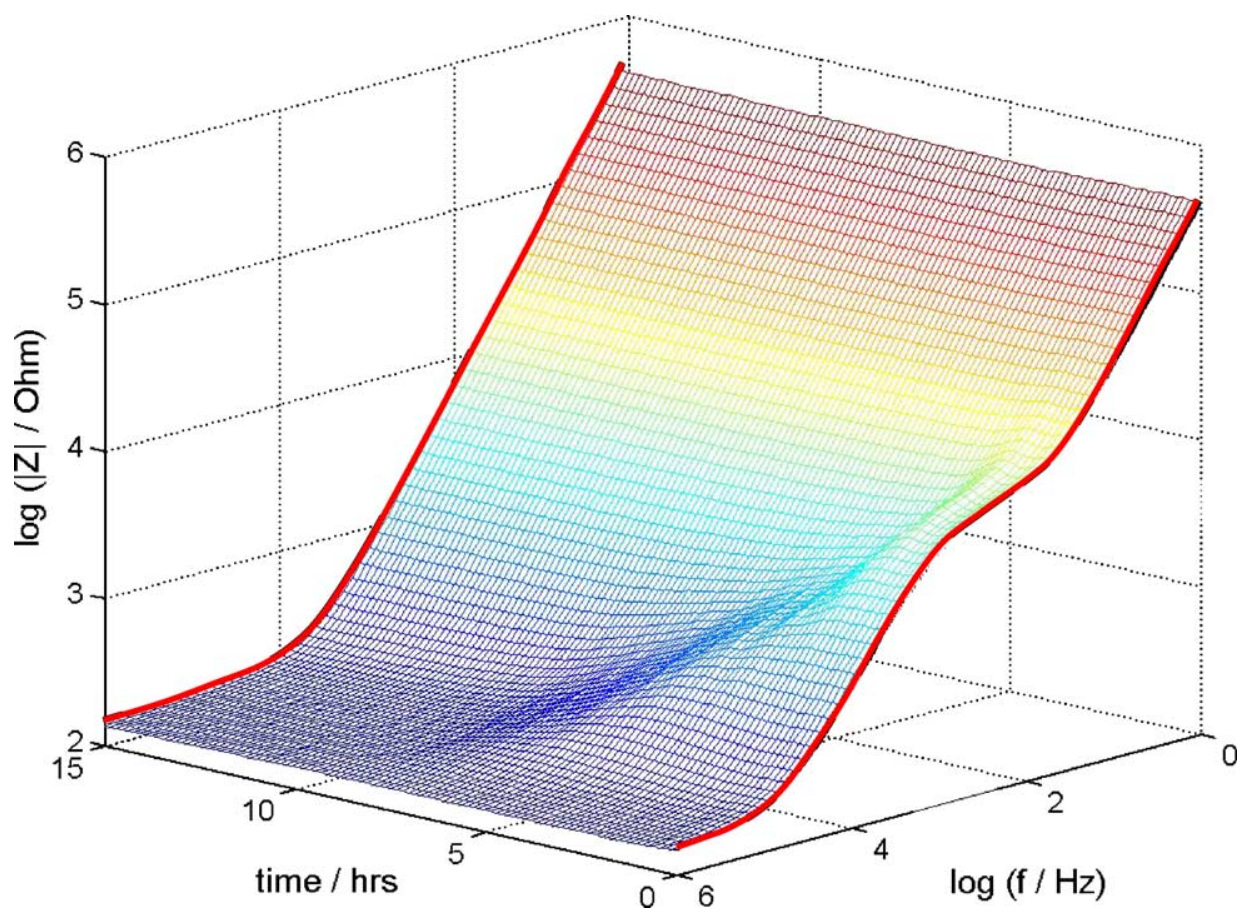

Fig. 4. Evolution of the impedance magnitude $|Z|$ along a frequency range from 1 to $10^{6} \mathrm{~Hz}$ when confluent micro-vessel endothelial cells are exposed to $25 \mu \mathrm{M}$ cycloheximide. After recording base line data cycloheximide was added $0.75 \mathrm{~h}$ after the first spectrum was recorded. Please note that the frequency axes has been reversed to provide a view on the impedance surface. The very first $(t=0 \mathrm{~h})$ and the very last $(t=15 \mathrm{~h})$ impedance spectrum recorded in this experiment are re-plotted in Fig. 5 in two-dimensional representation. 


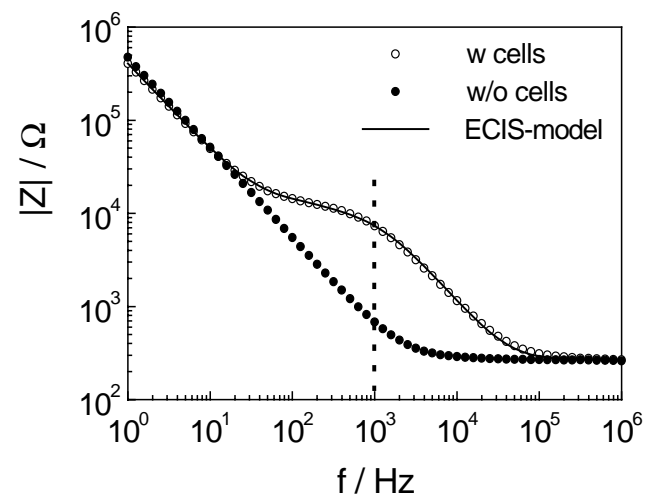

Fig. 5. Two-dimensional overlay of the frequency-dependent electrical impedance of gold-film electrodes covered with a confluent monolayer of micro-vessel endothelial cells before $(\bigcirc)$ and after $(O)$ exposure to $25 \mu \mathrm{M}$ cycloheximide for $15 \mathrm{~h}$. The corresponding spectra are highlighted in Fig. 4. The solid line represents the transfer function of the ECIS-model after the model parameters had been optimized by least-square techniques. The broken line indicates impedance values at a frequency of $1 \mathrm{kHz}$. In initial experiments we only recorded impedance data at this particular frequency to achieve best time resolution for apoptosis monitoring.

vital and apoptotic cells passes a maximum at roughly $1 \mathrm{kHz}$ indicating that impedance readings at this frequency are most sensitive to mirror the associated changes in cell morphology.

Thus, we first monitored impedance values at a sampling frequency of $1 \mathrm{kHz}$ (Fig. 6A) while a confluent monolayer of PBCEC was exposed to $25 \mu \mathrm{M} \mathrm{CHX}(\bigcirc)$ or a corresponding dose of DMSO $(\oplus)$. In the control experiment the addition of DMSO $(0.05 \%, \mathrm{v} / \mathrm{v})$ did not induce any significant perturbation in impedance indicating that the cell shape did not change. Addition of $25 \mu \mathrm{M} \mathrm{CHX}$ induces a rapid and monotonic decrease in impedance after an initial lag phase of approx. $0.5 \mathrm{~h}(\bigcirc)$. Within $6 \mathrm{~h}$ the impedance magnitude approaches values of a cell-free electrode. The time resolution was adjusted to $10 \mathrm{~min}$ but could have been improved many times if the experimental situation would have required so. To get a quantitative measure for the dynamics of apoptosis-induced changes we determined the time necessary for half-maximum reduction of the impedance at $1 \mathrm{kHz}$ $\left(t_{\mathrm{Z} 50}\right)$. Analysis of 19 time courses similar to the one shown in Fig. 6A returned a mean value for $t_{\mathrm{Z} 50}$ of $(1.2 \pm 0.1) \mathrm{h}$.

Since caspase- 3 has been reported to be the major protease that is responsible for apoptosis-induced proteolysis of various intracellular target proteins, we compared the time course of the impedance changes (Fig. 6A) with the time course of caspase- 3 activation upon CHX exposure. Fig. 6B (open columns) traces the activity of caspase-3 before and several hours after exposing the cells to $25 \mu \mathrm{M}$ CHX. For easy comparison the time markers $t_{1}$ (prior to CHX addition), $t_{2}$ ( $3 \mathrm{~h}$ after $\mathrm{CHX}$ addition) and $t_{3}(10 \mathrm{~h}$ after $\mathrm{CHX}$ addition) have also been included in Fig. 6A. The two time courses indicate that even very small and clearly sub-maximum levels of caspase- 3 activity go hand in hand with rather drastic changes in impedance. After $3 \mathrm{~h}$ of $\mathrm{CHX}$
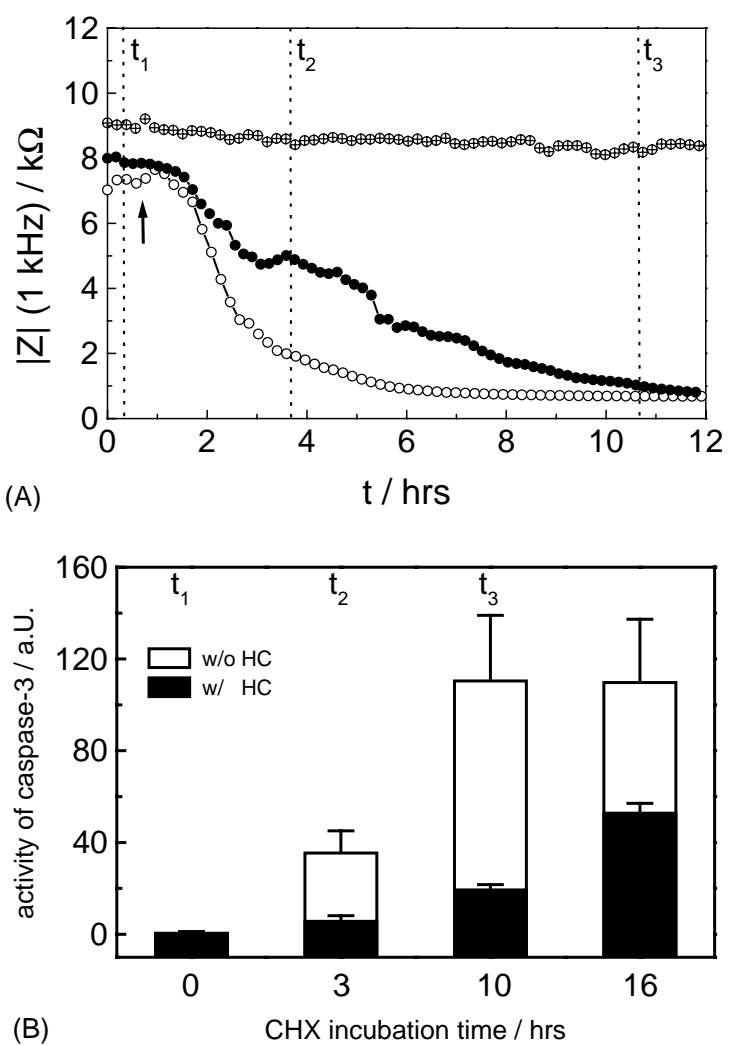

Fig. 6. (A) Time course of the impedance magnitude at a sampling frequency of $1 \mathrm{kHz}$ when confluent micro-vessel endothelial cells were exposed to $25 \mu \mathrm{M}$ cycloheximide $(-$ and $\bigcirc$ ). The cells were incubated in serum-free medium either with $(O)$ or without $(\bigcirc) 550 \mathrm{nM}$ hydrocortisone. In the control experiment (no hydrocortisone present) the cells were exposed to a corresponding dose of DMSO $(\oplus)$ that served as solvent for CHX. The corresponding control in presence of hydrocortisone (data not shown) behaved identically. Addition of CHX or DMSO is indicated by the arrow. (B) Time course of caspase-3 activity for micro-vessel endothelial cells upon exposure to $25 \mu \mathrm{M}$ cycloheximide. Open columns present enzyme activity in serum-free medium, whereas filled columns represent caspase- 3 activity in serum-free medium supplemented with $550 \mathrm{nM}$ hydrocortisone. The times $\left(t_{1}, t_{2}, t_{3}\right)$ when samples were taken and analyzed are indicated in (A) by broken lines.

exposure caspase- 3 activity amounts to less than $30 \%$ of its final value while the impedance of the cell layer at $1 \mathrm{kHz}$ has already decreased for more than $75 \%$ of its total change indicating the improved sensitivity of the impedance assay. After $10 \mathrm{~h}$ of CHX exposure the caspase- 3 activity has reached its maximum levels whereas the impedance changes are final after $6 \mathrm{~h}$. Accordingly, the time for half-maximum activation of caspase- 3 ( $\left.t_{\text {caspase }} 50\right)$ was determined to $(3.3 \pm 0.1) \mathrm{h}$ by fitting a sigmoidal curve (Boltzmann-type) to the recorded data. Taken together, this comparison indicates that in combination with ECIS recordings cell morphology is a very sensitive indicator for the onset of apoptosis since the cell shape responds drastically even to small increases in caspase-3 levels.

It has been reported for various cell types that glucocorticoids like dexamethasone or hydrocortisone are capable of reducing the level of apoptosis when it is initiated by 
Table 1

Kinetic parameters of cycloheximide-induced apoptosis in micro-vessel endothelial cells incubated in serum-free medium alone or in SFM supplemented with $550 \mathrm{nM}$ hydrocortisone (HC)

\begin{tabular}{llc}
\hline & $t_{\text {Z50 }}(\mathrm{h})$ & $t_{\text {caspase 50 }}(\mathrm{h})$ \\
\hline $\mathrm{SFM}$ & $1.2 \pm 0.1$ & $3.3 \pm 0.1$ \\
$\mathrm{SFM}+\mathrm{HC}$ & $3.0 \pm 0.3$ & $16 \pm 6$
\end{tabular}

$t_{\mathrm{z} 50}$ denotes the time necessary for half-maximum reduction of the electrical impedance at a sampling frequency of $1 \mathrm{kHz}$ after exposing the cells to $25 \mu \mathrm{M}$ cycloheximide (CHX). $t_{\text {caspase } 50}$ denotes the corresponding time necessary for half-maximum activation of caspase- 3 . The given values are mean \pm S.D. $(n>8)$

cytokines or serum-depletion (Wen et al., 1997; Messmer et al., 1999; Huang and Cidlowski, 1999). Thus, we addressed whether hydrocortisone when applied in physiological concentrations can retard the apoptosis-induced impedance decrease that we observed for PBCEC in our system. Fig. 6A compares the time course of the electrical impedance when a confluent monolayer of PBCEC was exposed to $25 \mu \mathrm{M}$ CHX in presence of $550 \mathrm{nM} \mathrm{HC} \mathrm{( \bullet )} \mathrm{with}$ the dataset discussed before $(O)$ that was recorded in absence of HC. In control experiments in which we only applied a corresponding volume of DMSO (data not shown) we could not detect any significant response of the cells similar to the control experiment in absence of HC $(\oplus)$. The figure shows that in presence of $\mathrm{HC}$ the decrease in electrical impedance is significantly slower and a biphasic time course is indicated. After an initial drop within the first $2.5 \mathrm{~h}$ the impedance values stabilize for $2 \mathrm{~h}$ before they eventually approach values of a cell-free electrode in an asymptotic fashion. From 24 experiments we determined the time for half-maximum reduction of impedance $t_{\mathrm{Z} 50}$ to $(3.0 \pm 0.3) \mathrm{h}$ in presence of $\mathrm{HC}$. Accordingly, physiological concentrations of $\mathrm{HC}$ increase $t_{\mathrm{Z} 50}$ by a factor of 2.5 for micro-vessel endothelial cells. We then addressed whether or not this HC-mediated retardation of apoptosis is also reflected in levels of caspase- 3 activity. The filled columns in Fig. 6B show the time course of caspase- 3 activation when PBCEC are exposed to CHX in presence of HC. Compared to the same experiment in absence of the glucocorticoid we found a significant reduction of caspase- 3 activity. Fitting the data with a sigmoidal curve (assuming the same final activity as in absence of $\mathrm{HC})$ returns the time needed for half-maximum caspase activation $t_{\text {caspase }} 50$ as $(16 \pm 6) \mathrm{h}$. Thus, the half-maximum activation is retarded almost by a factor of 5 . The characteristic times $t_{50}$ that describe the dynamics of apoptosis in the different assays are summarized in Table 1. Taken together, ECIS readings and caspase- 3 activity measurements consistently show the anti-apoptotic influence of hydrocortisone for PBCEC. Comparison of both time courses again confirms the improved sensitivity of the ECIS-based assay to indicate the onset of apoptotic changes. The mechanism by which glucocorticoids inhibit apoptosis is not well understood at the present time. And it is questionable whether the anti-apoptotic effect of glucocorticoids for different cells and
Table 2

Morphological parameters as extracted from ECIS readings for confluent micro-vessel endothelial cells cultured either in serum-free medium (SFM) or in SFM supplemented with $550 \mathrm{nM}$ hydrocortisone (HC)

\begin{tabular}{llll}
\hline & $R_{\mathrm{b}}\left(\Omega \mathrm{cm}^{2}\right)$ & $\alpha\left(\Omega^{0.5} \mathrm{~cm}\right)$ & $C_{\mathrm{m}}\left(\mu \mathrm{F} / \mathrm{cm}^{2}\right)$ \\
\hline SFM & $142 \pm 80$ & $34 \pm 9$ & $1.09 \pm 0.12$ \\
$\mathrm{SFM}+\mathrm{HC}$ & $470 \pm 140$ & $59 \pm 5$ & $1.16 \pm 0.13$
\end{tabular}

$R_{\mathrm{b}}$ denotes the electrical resistance between adjacent cells indicative for the establishment for barrier-forming cell-cell contacts. $\alpha$ expresses impedance contributions arising from the cell-substrate adhesion zone and is thus indicative for cell-substrate interactions. $C_{\mathrm{m}}$ abbreviates the capacitance of the plasma membrane. The given values are mean \pm S.D. $(n>8)$.

different apoptotic stimuli can be explained by one common mechanism.

After applying ECIS for simply monitoring the dynamics of CHX-induced changes in cell shape, we then made use of its analytical capabilities to find out more precisely what happens on the cellular level with respect to cell-cell and cell-matrix contacts and the time course of their modulation during apoptosis. We thus recorded impedance data over the entire frequency range from $1 \mathrm{~Hz}$ to $1 \mathrm{MHz}$ for both conditions $( \pm \mathrm{HC})$ and analyzed the data by means of the ECIS-model previously derived by Giaever and Keese (1991). By applying this model to the recorded impedance data we can distinguish between impedance contributions due to cell-cell contacts and those due to cell-substrate adhesion. $R_{\mathrm{b}}$ denotes the specific resistance between adjacent cells and therefore reflects the integrity of tight junctions. The parameter $\alpha$ describes the frequency-dependent impedance contribution arising from cell-substrate adhesion. The morphology of the plasma membrane is mirrored in the plasma membrane capacitance $C_{\mathrm{m}}$. The solid line in Fig. 5 demonstrates the good agreement between the experimental data and the ECIS-model after parameter optimization. Such an analysis revealed significant differences between PBCEC monolayers that were either kept in $\mathrm{HC}$-supplemented or HC-free medium, respectively, even prior to any CHX challenge. The resistance between cells $R_{\mathrm{b}}$ is elevated roughly three-fold from $(140 \pm 80) \Omega \mathrm{cm}^{2}$ in the absence of $\mathrm{HC}$ to $(470 \pm 140) \Omega \mathrm{cm}^{2}$ when $\mathrm{HC}$ is present in $550 \mathrm{nM}$ concentrations. The value of $\alpha$ for unchallenged PBCEC cultured without $\mathrm{HC}$ amounts to $(34 \pm 9) \Omega^{0.5} \mathrm{~cm}$ and is only half the value of $(59 \pm 5) \Omega^{0.5} \mathrm{~cm}$ that we find in presence of HC. The membrane capacitances $\mathrm{C}_{\mathrm{m}}$ were not significantly affected and were found to be very close to $1 \mu \mathrm{F} / \mathrm{cm}^{2}$ as it is typically found for smooth cellular plasma membranes. ECIS parameters for unchallenged PBCECs $( \pm \mathrm{HC})$ are summarized in Table 2 . The impact of HC on endothelial barrier function as revealed by the resistance $R_{\mathrm{b}}$ is consistent with previous studies from our laboratory in which we described the reduction of paracellular permeability for sucrose upon exposure of PBCEC to hydrocortisone (Hoheisel et al., 1998). ECIS analysis as performed here furthermore reveals that $\mathrm{HC}$ does not only strengthen the 

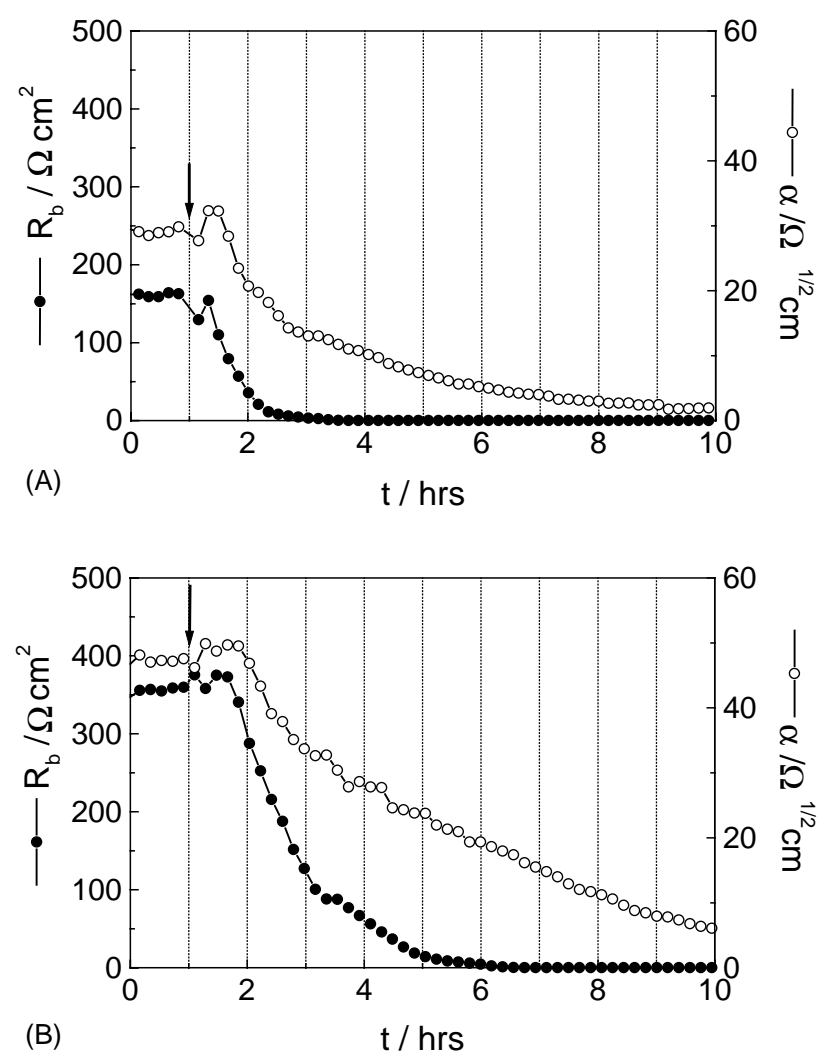

Fig. 7. Time courses of the ECIS parameters $R_{\mathrm{b}}(\Theta)$ and $\alpha(\bigcirc)$ when confluent layers of micro-vessel endothelial cells were exposed to $25 \mu \mathrm{M}$ cycloheximide (CHX) at the time indicated by the arrows. Cells were incubated either in the absence (A) or in presence of $550 \mathrm{nM}$ hydrocortisone (B).

tight junctions of PBCEC, but also enforces cell-substrate interactions providing an improved substrate adhesion of the cells. The morphology of the plasma membrane as mirrored in the membrane capacitance $C_{\mathrm{m}}$ is not altered in any significant manner which was verified by electron microscopy revealing almost unfolded membranes for both conditions (data not shown).

Fig. 7 shows typical time courses of the parameters $R_{\mathrm{b}}(\bullet)$ and $\alpha(O)$ derived from ECIS raw data for confluent PBCEC incubated in serum-free medium only (A) or in presence of $550 \mathrm{nM}$ HC (B). The cells were exposed to $25 \mu \mathrm{M}$ CHX at the times indicated by arrows. Without HC-supplementation $R_{\mathrm{b}}$ decreases very fast and eventually vanishes within $2 \mathrm{~h}$ (Fig. 7A). Since the time course of $R_{\mathrm{b}}(\bullet)$ primarily mirrors the modulation of barrier-forming cell-cell contacts (tight junctions), the data implies that these contacts are functionally completely disintegrated within $2 \mathrm{~h}$ of $\mathrm{CHX}$-exposition. For the same cell population $\alpha$ shows a different time course (○). $\alpha$ apparently decreases in two steps starting from values around $30 \Omega^{0.5} \mathrm{~cm}$. During the first $2 \mathrm{~h}$ after addition of CHX we monitored a fast drop of $\alpha$ to roughly half the starting values. After a delay $\alpha$ then decreased asymptotically to zero. The first phase of $\alpha$-decrease parallels the reduction of $R_{\mathrm{b}}$. Throughout the pool of datasets we consistently found a tendency of $\alpha$ to decrease in a biphasic fashion as it is indicated in Fig. 7A.

Exposing confluent PBCECs to $25 \mu \mathrm{M} \mathrm{CHX}$ in presence of HC (Fig. 7B), prolongs the time until both parameters, $R_{\mathrm{b}}$ and $\alpha$, become insignificantly low. In terms of cell morphology, this means that functional disintegration of cell-cell and cell-matrix contacts occurs at later times of exposure to CHX. It takes almost $5 \mathrm{~h}$ for $R_{\mathrm{b}}$ to completely vanish. Although $\alpha$ declines monotonically with the same indications for a mechanism that relies on two time constants, it does not completely disappear till the end of the experiment. Consistently, phase contrast microscopy revealed that the cell bodies were still present on the electrode surface after $10 \mathrm{~h}$ of incubation with CHX but apparently cell-substrate contacts had been altered significantly.

The observed functional changes in cell-cell and cell-substrate contacts as monitored with ECIS agree with more structural studies reported by others. Most notably, caspase- 3 was recently found to cleave actin, the monomeric building block of cytoskeletal microfilaments (Mashima et al., 1995; Mashima et al., 1997). These microfilaments span the cytoplasm running from one point of substrate anchorage to the next and they are furthermore linked to sites of cell-cell contacts forming a belt like structure along the cell peripherie. Dependent on the local concentration of monomeric actin and many other factors they can dynamically expand or contract. Thus, caspase-3 mediated proteolysis of actin may explain the observed changes in both, cell-cell and cell-substrate contacts. Furthermore Bannerman et al. (1998) found for apoptotic endothelial cells derived from bovine pulmonary arteries that activated caspases cleave $\beta$ - and $\gamma$-catenin. Both catenins are molecular key constituents of the adherens junctions, a class of cell-cell contacts that interconnect the microfilament system of adjacent cells mechanically through the intercellular cleft (Alberts et al., 1994). Herein, catenins are the molecular linker between the microfilaments and specialized transmembrane proteins, so-called cadherins, that make contact to cadherins on the opposing cell surface. Herren et al. (1998) furthermore found cleavage of the extracellular domains of VE-cadherin in apoptotic endothelial cells by secreted matrix metallo-proteinases (MMP). Thus, the rapid decrease of impedance after induction of apoptosis may be the result of both processes: disintegration of adherens junctions in concert with proteolysis of actin filaments.

In order to probe the degradation of PBCEC cell-cell contacts as recorded with ECIS upon exposure to CHX from a more structural viewpoint we immuno-stained for two proteins that are associated with barrier-forming cell-cell contacts (Figs. 8 and 9). Fig. 8 shows fluorescence microscopic images of immuno-stainings directed against zonula occludens protein 1 , the first protein that was identified to be a unique constituent of the tight junctions. ZO-1 is an intracellular peripheral membrane protein that serves as a linker protein between the actin cytoskeleton and the junction forming transmembrane proteins (Wegener et al., 1996). We 


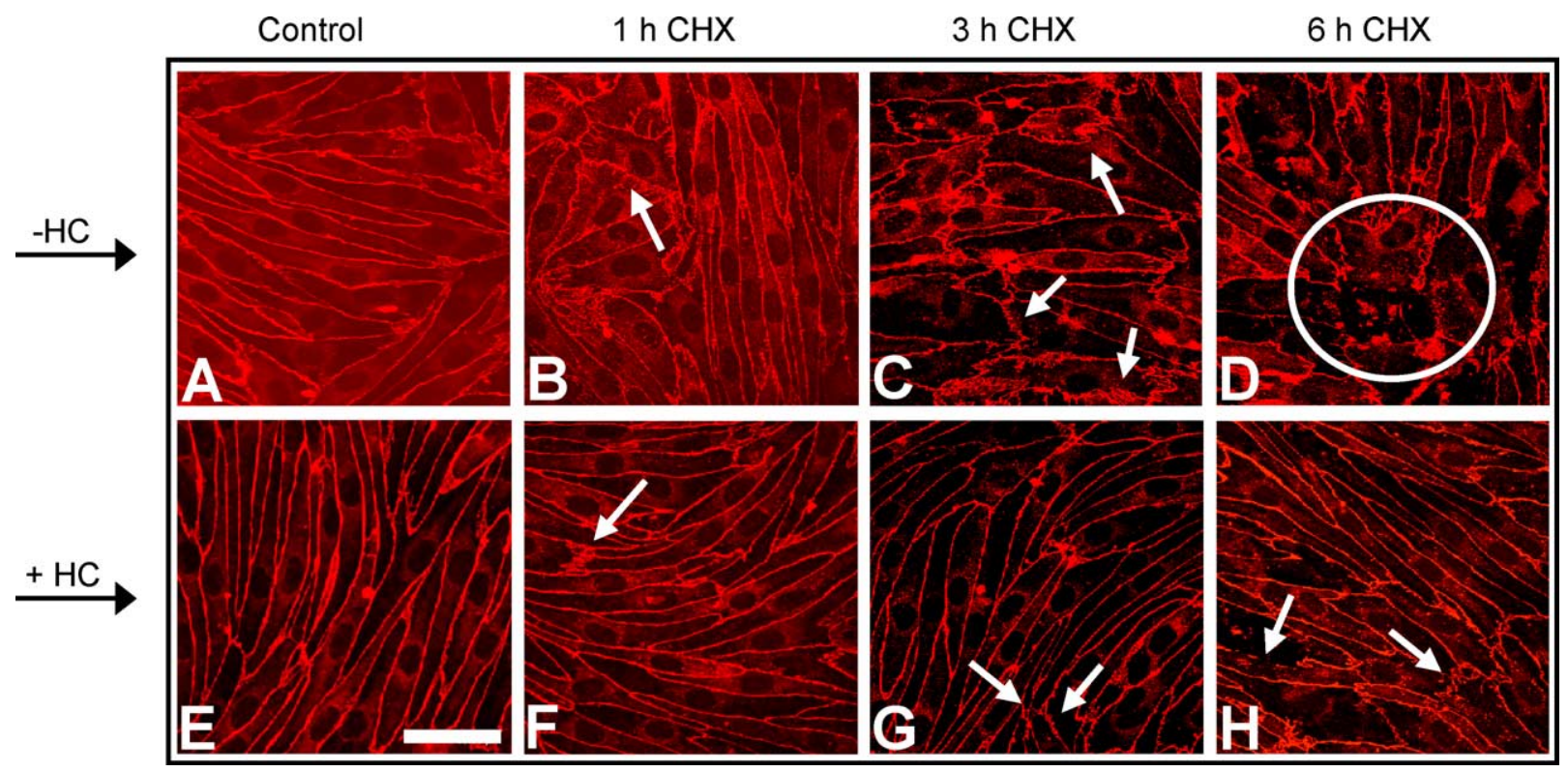

Fig. 8. Immuno-cytochemical staining for the tight junction associated protein ZO-1 when confluent layers of micro-vessel endothelial cells were exposed to $25 \mu \mathrm{M}$ cycloheximide (CHX) for increasing exposure times either in absence (A-D) or presence of $550 \mathrm{nM}$ hydrocortisone (E-H). The scale bar corresponds to $40 \mu \mathrm{m}$. HC: hydrocortisone.

prepared samples of PBCEC monolayers that were cultured in serum-free medium without $\mathrm{HC}$ addition (upper panel) or in presence of $\mathrm{HC}$ (lower panel). All samples-except controls in (A) and (E) - were exposed to $25 \mu \mathrm{M} \mathrm{CHX}$ and stained at the times given in the figure. As expected for a tight junctions associated protein, ZO-1 immuno-reactivity was almost exclusively localized at the cell borders under both conditions $( \pm \mathrm{HC})$. In cells that had not been challenged with $\mathrm{CHX}$ ( $\mathrm{A}$ and $\mathrm{E}$ ) differences in the staining pattern of
ZO-1 for both conditions are not very pronounced and do not mirror the measured differences in $R_{\mathrm{b}}$ (compare Table 2) directly. If at all, staining of the cell perimeter appears somewhat more homogeneous for PBCEC cultured in presence of $\mathrm{HC}$ (E) compared to cells grown in its absence (A). One hour after apoptosis had been triggered the cell border staining starts to get a fuzzy appearance, invaginated with structures that point to the center of the cell. These morphological alterations are very likely due to cell contraction and indicate loss

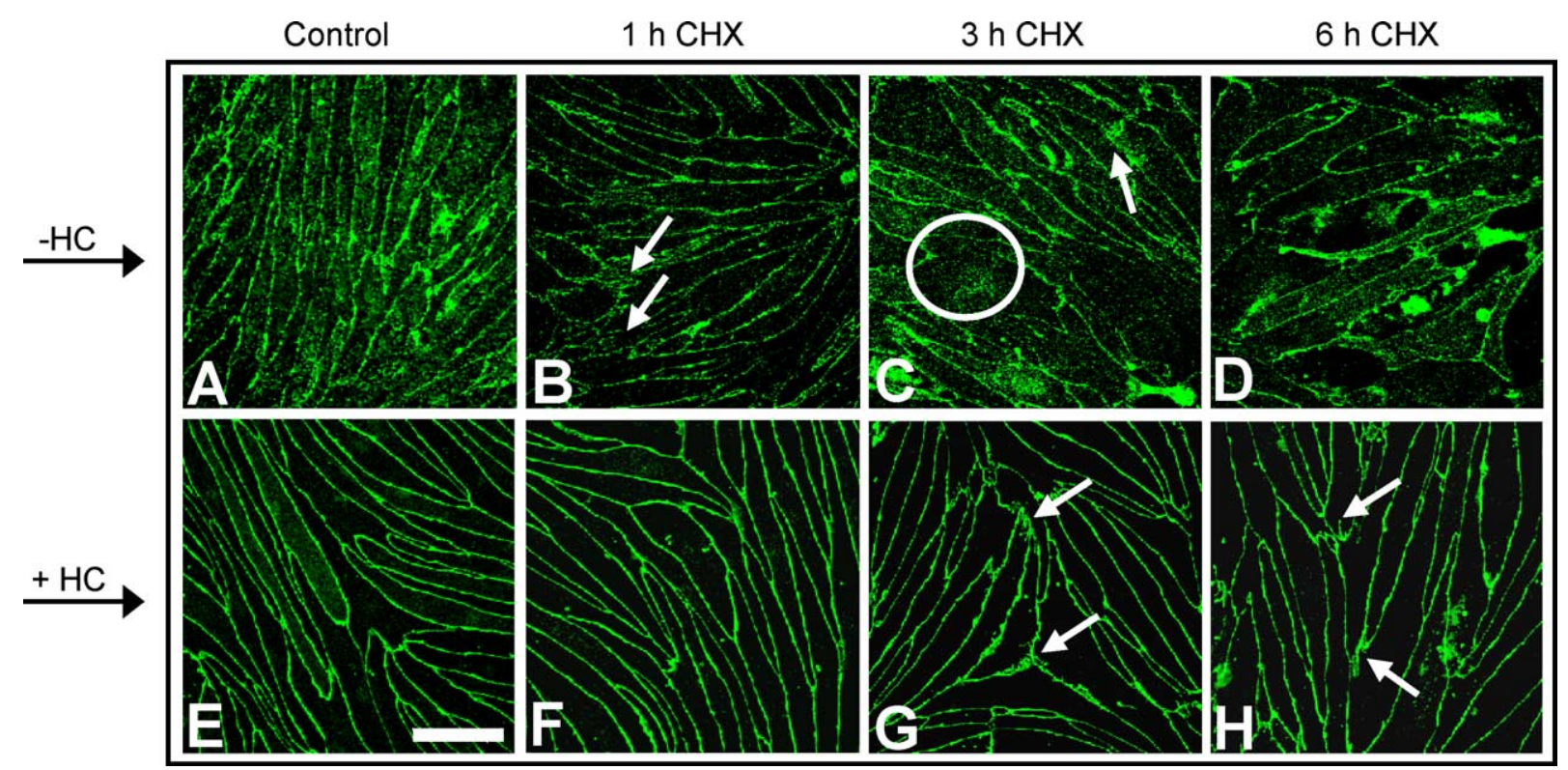

Fig. 9. Immuno-cytochemical staining for the tight junction transmembrane protein occludin when confluent layers of micro-vessel endothelial cells were exposed to $25 \mu \mathrm{M}$ cycloheximide (CHX) for increasing exposure times either in absence (A-D) or presence of $550 \mathrm{nM}$ hydrocortisone (E-H). The scale bar corresponds to $40 \mu \mathrm{m}$. HC: hydrocortisone. 
of cell-cell contacts although no open intercellular spaces could be observed. Comparing the ZO-1 staining at identical times for conditions with and without $\mathrm{HC}$ clearly shows that the lateral density of defects in the cell-cell contact pattern is significantly higher in cells that were grown without $\mathrm{HC}$. Please note that after $6 \mathrm{~h}$ of $\mathrm{CHX}$ exposure in the absence of $\mathrm{HC}$ individual cells have lost the cell border staining entirely (circle in Fig. 8D), whereas in presence of HC only discontinuities within the cell borders occurred. Taken together these structural snap shots of ZO-1 distribution during apoptosis confirm the HC-mediated retardation of apoptotic disintegration of cell-cell contacts as shown in the time courses of $\mathrm{Rb}$ in Fig. 7. When cells were kept in absence of $\mathrm{HC}$ the electrical resistance between adjacent cells (Fig. 7A) $R_{\mathrm{b}}$ is reduced to less $30 \Omega \mathrm{cm}^{2}$ within $1 \mathrm{~h}$ and is close to $0 \Omega \mathrm{cm}^{2}$ after $3 \mathrm{~h}$. At the same times $R_{\mathrm{b}}$ amounts to more than $250 \Omega \mathrm{cm}^{2}(1 \mathrm{~h})$ or $50 \Omega \mathrm{cm}^{2}(3 \mathrm{~h})$ with the apoptosis inhibitor $\mathrm{HC}$ present in the medium. Apparently ECIS readings that report on functional changes of the tight junctions are significantly more sensitive to apoptic changes than immuno-stainings that rather indicate structural alterations. It is noteworthy that $R_{\mathrm{b}}$ can drop to values very close to zero without any visible intercellular gaps within the cell monolayer. This is consistent with previous studies in which we and others examined continuous monolayers of cells that express only very leaky tight junctions (e.g. macrovascular endothelial cells). ECIS analysis for these cell monolayers provides $R_{\mathrm{b}}$ values of $3 \Omega \mathrm{cm}^{2}$ and below (Giaever and Keese, 1991; Wegener et al., 1999) with no cells missing in the cell sheet.

We also stained for an integral protein of the tight junctions named occludin. Occludin was the first transmembrane protein that was exclusively assigned to the barrier-forming cell contacts. It is linked intracellularly to the actin cytoskeleton via ZO-1. Fig. 9 compares fluorescence micrographs of occludin immuno-stainings when confluent PBCEC were exposed to $25 \mu \mathrm{M}$ CHX for the indicated times. The upper panel holds images recorded for cells in absence of $\mathrm{HC}$ whereas the lower panel shows the situation in presence of HC. The observed cell border staining is very similar to the one obtained for ZO-1 (Fig. 8). In general, the occludin staining is more exclusively localized to the cell contacts in presence of $\mathrm{HC}$ whereas in its absence there is some diffuse background. The reason for this is unclear although the staining protocol was identical. Similar to the observations described for the ZO-1 experiments the staining pattern becomes irregular with discontinuities and invaginations upon exposure to $\mathrm{CHX}$. And again, these irregularities within the cell border staining are more pronounced when $\mathrm{HC}$ is omitted from the culture medium (A-D). The occludin staining provides another independent prove for the apoptosis-induced changes within the tight junctions of micro-vessel endothelial cells and the retarding effect of $\mathrm{HC}$.

A more general comparison between the two experimental approaches that have been discussed in the previous section (immuno-staining versus ECIS) underlines two unique methodological advantages of the bioelectrical assay: (i)
ECIS provides quantitative data that can be easily analyzed and characterized by quantities like $t_{\text {Z50 }}$. Describing the structural changes that are provided by the images in Figs. 8 and 9 by an easy-to-grasp parameter requires, however, elaborate image analysis techniques. (ii) ECIS readings report the functional status of the cells rather than any structural information. In many instances a functional parameter is the more significant and relevant information. (iii) The ECIS approach is highly automated and computerized. It does not require a lot of manpower since one and the same culture is non-invasively followed with time instead of sacrificing a culture for each time point.

\section{Conclusion}

In summary this study demonstrated the capabilities of a bioelectrical hybrid device consisting of an endothelial cell monolayer with unique barrier properties and the electrochemical ECIS technique to monitor the dynamics of apoptosis in unprecedented time resolution. The three-dimensional shape of the cells served as the ultimate sensor for the onset and propagation of programmed cell death which proved to be significantly more sensitive than caspase- 3 activity or structural changes in the cell-cell contacts. The technical benefits of the electrochemical ECIS measurements are (i) its non-invasive performance, (ii) the quantitative nature of the recorded data, (iii) access to functional changes in the status of the cells rather than structural, and (iv) the ability to run ECIS experiments completely automated and computer-controlled. ECIS readings by themselves provide multiple information about the cells on the electrode surface in one experiment that are otherwise only available with a combination of cytological and biochemical techniques requiring a corresponding number of cellular samples. In combination with appropriate cells used as sensory elements on the electrode surface-even genetically engineered cell lines-ECIS may serve as a whole-cell biosensor in cytotoxicity studies but also in the course of drug development.

\section{Acknowledgements}

Financial support granted by the DFG to JW is gratefully acknowledged (Grant No. WE 2721/1-1). The authors would like to thank S. Hüwel for her help and expertise with the primary cultures, S. Idel for her support with the apoptosis assays as well as S. Dirks and D. Abrams for software engineering.

\section{References}

Bannerman, D.D., Sathyamoorthy, M., Goldblum, S.E., 1998. Bacterial lipopolysaccharide disrupts endothelial monolayer integrity and survival signaling events through caspase cleavage of adherens junction proteins. J. Biol. Chem. 273 (52), 35371-35380. 
Bradbury, M.W., 1993. The blood-brain barrier. Exp. Physiol. 78 (4), 453-472.

Franke, H., Galla, H., Beuckmann, C.T., 2000. Primary cultures of brain microvessel endothelial cells: a valid and flexible model to study drug transport through the blood-brain barrier in vitro. Brain Res. Brain Res. Protoc. 5 (3), 248-256.

Fromter, E., 1972. The route of passive ion movement through the epithelium of Necturus gallbladder. J. Membr. Biol. 8 (3), 259-301.

Giaever, I., Keese, C.R., 1991. Micromotion of mammalian cells measured electrically. Proc. Natl. Acad. Sci. U.S.A. 88 (17), 7896-7900.

Giaever, I., Keese, C.R., 1993. A morphological biosensor for mammalian cells. Nature 366 (6455), 591-592.

Herren, B., Levkau, B., Raines, E.W., Ross, R., 1998. Cleavage of beta-catenin and plakoglobin and shedding of VE-cadherin during endothelial apoptosis: evidence for a role for caspases and metalloproteinases. Mol. Biol. Cell 9 (6), 1589-1601.

Hoheisel, D., Nitz, T., Franke, H., Wegener, J., Hakvoort, A., Tilling, T., Galla, H.J., 1998. Hydrocortisone reinforces the blood-brain barrier properties in a serum free cell culture system. Biochem. Biophys. Res. Commun. 244 (1), 312-316.

Hu, X., Yee, E., Harlan, J.M., Wong, F., Karsan, A., 1998. Lipopolysaccharide induces the antiapoptotic molecules, A1 and A20, in microvascular endothelial cells. Blood 92 (8), 2759-2765.

Huang, S.T., Cidlowski, J.A., 1999. Glucocorticoids inhibit serum depletion-induced apoptosis in $\mathrm{T}$ lymphocytes expressing $\mathrm{Bcl}-2$. FASEB J. 13 (3), 467-476.

Keese, C.R., Giaever, I., 1994. A biosensor that monitors cell morphology with electrical fields. IEEE Eng. Med. Biol. 13 (3), 402-408.

Leist, M., Jaattela, M., 2001. Four deaths and a funeral: from caspases to alternative mechanisms. Nat. Rev. Mol. Cell Biol. 2 (8), 589-598.

Lo, C.M., Keese, C.R., Giaever, I., 1994. pH changes in pulsed $\mathrm{CO}_{2}$ incubators cause periodic changes in cell morphology. Exp. Cell Res. 213 (2), 391-397.

Mashima, T., Naito, M., Fujita, N., Noguchi, K., Tsuruo, T., 1995. Identification of actin as a substrate of ICE and an ICE-like protease and involvement of an ICE-like protease but not ICE in VP-16-induced U937 apoptosis. Biochem. Biophys. Res. Commun. 217 (3), 11851192.
Mashima, T., Naito, M., Noguchi, K., Miller, D.K., Nicholson, D.W., Tsuruo, T., 1997. Actin cleavage by CPP-32/apopain during the development of apoptosis. Oncogene 14 (9), 1007-1012.

McConkey, D.J., 1998. Biochemical determinants of apoptosis and necrosis. Toxicol. Lett. 99 (3), 157-168.

Messmer, U.K., Briner, V.A., Pfeilschifter, J., 1999. Tumor necrosis factor-alpha and lipopolysaccharide induce apoptotic cell death in bovine glomerular endothelial cells. Kidney Int. 55 (6), 2322-2337.

Reddy, L., Wang, H.S., Keese, C.R., Giaever, I., Smith, T.J., 1998. Assessment of rapid morphological changes associated with elevated cAMP levels in human orbital fibroblasts. Exp. Cell Res. 245 (2), 360-367.

Robertson, J.D., Orrenius, S., 2000. Molecular mechanisms of apoptosis induced by cytotoxic chemicals. Crit. Rev. Toxicol. 30 (5), 609-627.

Takahashi, A., 1999. Caspase: executioner and undertaker of apoptosis. Int. J. Hematol. 70 (4), 226-232.

Thompson, C.B., 1995. Apoptosis in the pathogenesis and treatment of disease. Science 267 (5203), 1456-1462.

Tiruppathi, C., Malik, A.B., Del Vecchio, P.J., Keese, C.R., Giaever, I., 1992. Electrical method for detection of endothelial cell shape change in real time: assessment of endothelial barrier function. Proc. Natl. Acad. Sci. U.S.A. 89 (17), 7919-7923.

Wegener, J., Sieber, M., Galla, H.J., 1996. Impedance analysis of epithelial and endothelial cell monolayers cultured on gold surfaces. J. Biochem. Biophys. Methods 32 (3), 151-170.

Wegener, J., Zink, S., Rosen, P., Galla, H., 1999. Use of electrochemical impedance measurements to monitor beta-adrenergic stimulation of bovine aortic endothelial cells. Pflugers. Arch. 437 (6), 925-934.

Wegener, J., Hakvoort, A., Galla, H.J., 2000. Barrier function of porcine choroid plexus epithelial cells is modulated by cAMP-dependent pathways in vitro. Brain Res. 853 (1), 115-124.

Wen, L.P., Madani, K., Fahrni, J.A., Duncan, S.R., Rosen, G.D., 1997. Dexamethasone inhibits lung epithelial cell apoptosis induced by IFN-gamma and Fas. Am. J. Physiol. 273 (5 Pt. 1), L 921-L 929.

Wyllie, A.H., Kerr, J.F., Currie, A.R., 1980. Cell death: the significance of apoptosis. Int. Rev. Cytol. 68, 251-306.

Zaucke, F., Zöltzer, H., Krug, H.F., 1998. Dose-dependent induction of apoptosis or necrosis in human cells by organotin compounds. Fresenius J. Anal. Chem. 361, 386-392. 